
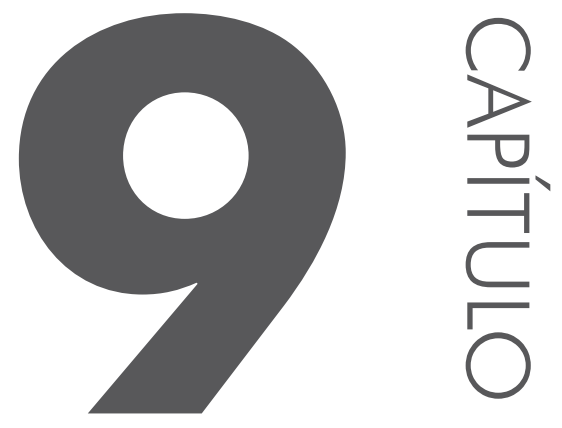

\title{
MARCAS LINGUISTICAS DE POLIDEZ E SEXO/GÊNERO
}

\author{
Kelly Carine dos Santos \\ Andréia Silva Araujo
}

\section{INTRODUC̣ÃO}

Desde a década de 1970, com o estudo pioneiro de Robin Lakoff, diversos estudos têm evidenciado a relação entre a linguagem e o sexo/ gênero do falante. Se outrora a diferença na fala de homens e mulheres estava relacionada ao papel desempenhado por cada um na sociedade, atualmente, em um momento em que indivíduos de ambos os sexos/gêneros desempenham os mesmos papéis sociais, as diferenças entre as formas de falar podem estar relacionadas a fatores pragmáticos.

Temos como objetivo, neste capítulo, analisar os efeitos do fator sexo/ 
gênero no uso de duas estratégias linguísticas de polidez: a forma pronominal nós/a gente e a forma verbal futuro do pretérito.

Para desenvolvermos a pesquisa nessa perspectiva, utilizamos como corpus a amostra de fala Rede Social de Informantes Universitários de Itabaiana/SE (ARAUJO, SANTOS, FREITAG, 2014). Esta amostra é composta por interações conduzidas - os próprios informantes conduzem a interação - coletadas a partir de um grupo focal constituído especificamente para captar as nuanças de polidez, tanto em seus aspectos pragmáticos quanto sociolinguísticos.

\subsection{POLIDEZ LINGUÍSTICA}

Brown e Levinson (2011 [1987]) concebem a polidez como uma atividade estratégica racional e defendem que as diferentes formas de polidez atendem às diferentes necessidades sociocomunicativas. Mesmo admitindo que o que é "polido" varia de cultura para cultura, já que em uma cultura um comportamento pode ser polido, e em outra ele pode ser visto como uma ofensa, os autores partem do princípio da universalidade da polidez, por acreditarem que, independente da cultura, os interlocutores sabem que têm uma imagem a preservar nas interações.

Os autores inspiram-se na noção metafórica de face da teoria de Goffman (1967) e baseiam-se em uma pessoa-modelo, a qual fala fluentemente uma língua natural e possui duas propriedades importantes para esclarecer o uso da linguagem - racionalidade e face. Distinguem também dois tipos de polidez: a que envolve estratégias de face positiva, e a que envolve estratégias de face negativa, conceito central desse modelo.

A face que apresenta o lado negativo está relacionada à nossa intimidade e ao desejo de não imposição, já a que apresenta o lado positivo se relaciona à imagem que queremos passar socialmente, a que queremos apresentar aos outros, com o intuito de ter o reconhecimento ou aprovação. A face é entendida como atributo pessoal ou qualidade que cada um tenta proteger ou melhorar, é a autoimagem que cada um constrói socialmente de si, podendo ela ser perdida, mantida ou melhorada (BROWN; LEVINSON, 2011 [1987]). E já que as interações são lugares propícios para os conflitos, queremos proteger nossa face contra possíveis danos quando interagimos com outrem.

Esses danos às faces podem ser causados por atos que ameaçam as faces, tanto do falante quanto do ouvinte, no momento das interações, denominados por Brown e Levinson (2011[1987], p. 60) como face-threatening acts (FTAs). Estes atos ameaçadores da face são divididos em quatro tipos: 
- Atos ameaçadores da face negativa do locutor: promessas ou qualquer coisa que possa atingir nossa intimidade;

- Atos ameaçadores da face positiva do locutor: pedidos de desculpas, autocríticas, confissões;

- Atos ameaçadores da face negativa do interlocutor: ofensas, pedidos, perguntas indiscretas;

- Atos ameaçadores da face positiva do interlocutor: críticas, insultos, censuras.

Assim, as faces, positiva e negativa, são alvos de ameaças e objetos de desejo de preservação, que terão de ser conservadas a fim de manterem o equilíbrio nas relações interpessoais. Para preservar a face e manter a relação sem atritos, o falante faz uso de um conjunto de estratégias linguísticas, que chamamos de estratégias de polidez, utilizadas a depender das circunstâncias de execução de um FTA, como esquematizado na figura 1.

Figura 1: Circunstâncias que determinam as escolhas das estratégias

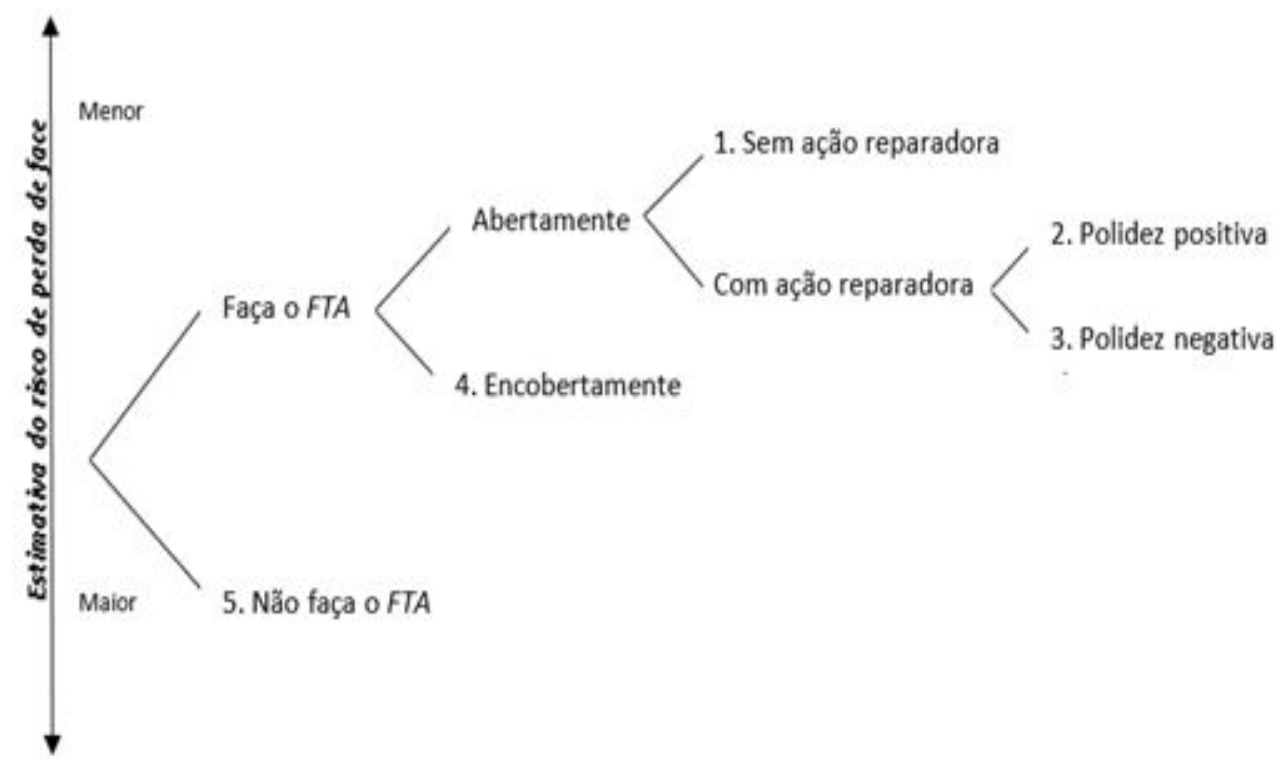

Fonte: Brown e Levinson (2011 [1987], p. 60, tradução nossa).

Brown e Levinson (2011 [1987]) propõem que o falante escolhe se vai realizar ou não o FTA; uma vez que ele opte pela realização, pode assumir uma posição encoberta, que o distancia dos efeitos do FTA, ou uma posição aberta, que pode ser realizada com ação reparadora ou sem ação 
reparadora. A partir do momento em que o falante opta por realizar um FTA abertamente com ação reparadora, ele decide se utiliza estratégias de polidez positiva ou negativa.

Quadro 1: Estratégias de polidez

\begin{tabular}{|c|c|c|}
\hline Estratégias de polidez positiva & Estratégias de polidez negativa & Estratégias de polidez encoberta \\
\hline $\begin{array}{l}\text { 1. Observar o outro; } \\
\text { 2. Exagerar interesses, } \\
\text { aprovações e empatia } \\
\text { pelo outro; } \\
\text { 3. Intensificar o interesse } \\
\text { pelo outro; } \\
\text { 4. Usar marcadores de } \\
\text { identidade grupal; } \\
\text { 5. Procurar acordo; } \\
\text { 6. Evitar desacordos; } \\
\text { 7. Pressupor e declarar } \\
\text { pontos em comum; } \\
\text { 8. Brincar, fazer piadas; } \\
\text { 9. Expressar os conhe- } \\
\text { cimentos sobre os } \\
\text { desejos do outro; } \\
\text { 10. Oferecer, prometer; } \\
\text { 11. Ser otimista; } \\
\text { 12. Incluir os interlocutores } \\
\text { na atividade; } \\
\text { 13. Dar ou pedir razões, } \\
\text { ou explicações; } \\
\text { 14. Declarar ou explicitar } \\
\text { reciprocidade; } \\
\text { 15. Dar presentes ao } \\
\text { ouvinte (bens, simpatia, } \\
\text { cooperação). }\end{array}$ & $\begin{array}{l}\text { 1. Ser convencionalmen- } \\
\text { te indireto; } \\
\text { 2. Questionar, atenuar; } \\
\text { 3. Ser pessimista; } \\
\text { 4. Minimizar a imposi- } \\
\text { ção; } \\
\text { 5. Mostrar deferência; } \\
\text { 6. Pedir desculpas; } \\
\text { 7. Impessoalizar o falan- } \\
\text { te e o ouvinte; } \\
\text { 8. Declarar o FTA como } \\
\text { uma regra geral; } \\
\text { 9. Nominalizar; } \\
\text { 10. Mostrar abertamente } \\
\text { que está assumindo } \\
\text { um débito com o } \\
\text { interlocutor. }\end{array}$ & $\begin{array}{l}\text { 1. Dar dicas; } \\
\text { 2. Dar pistas de associa- } \\
\text { ção; } \\
\text { 3. Pressupor; } \\
\text { 4. Subestimar; } \\
\text { 5. Exagerar; } \\
\text { 6. Usar tautologias; } \\
\text { 7. Usar contradições; } \\
\text { 8. Ser irônico; } \\
\text { 9. Usar metáforas; } \\
\text { 10. Fazer perguntas retó- } \\
\text { ricas; } \\
\text { 11. Ser ambíguo; } \\
\text { 12. Ser vago; } \\
\text { 13. Ser generalizador; } \\
\text { 14. Deslocar o ouvinte; } \\
\text { 15. Ser incompleto, utilizar } \\
\text { elipse. }\end{array}$ \\
\hline
\end{tabular}

Fonte: Brown e Levinson (2011 [1987], tradução nossa). 
As estratégias de polidez positiva são direcionadas com intuito de reparar a face positiva do destinatário ou expressar interesse pelo outro, que ao contrário da polidez negativa, nem sempre será corretora de face violada por um FTA. Segundo Brown e Levinson (2011[1987]), as realizações linguísticas de polidez positiva, em muitos casos, podem representar desejos e conhecimentos compartilhados. Já as estratégias de polidez negativa são utilizadas em ações corretoras da face negativa do interlocutor, e geralmente usadas como forma de distanciamento social. A polidez negativa, diferente da polidez positiva, tem a função específica de minimizar os efeitos de um FTA. E as estratégias de polidez encobertas são aquelas que permitem que o falante produza um FTA sem se responsabilizar por ele, deixando a interpretação do seu registro de fala a critério do ouvinte. Nesses casos, o falante diz menos do que o necessário ou até mesmo algo diferente do que ele quer dizer.

Tais estratégias de polidez - positivas, negativas e encobertas - podem nos levar a um continuum que vai do menos polido ao mais polido, conforme a figura 2, em que serão utilizadas estratégias menos polidas e mais diretas quando a ameaça à face for baixa, e necessitará de estratégias mais polidas e mais indiretas quando a ameaça à face for alta.

\section{Figura 2: Continuum do grau de polidez}

- polido

\section{+ polido}

Para manifestar polidez e fazer emergir esses tipos de estratégias, o informante/falante conta com um repertório de marcas linguísticas, como, por exemplo: formas verbais (futuro do pretérito, imperfeito do indicativo e do subjuntivo etc.), perguntas indiretas, verbos modais (creio/acho/ imagino), enunciados justificativos ou explicativos, formas pronominais nós/a gente (cf. ROSA, 1992), entre outras. Dentre as marcas linguísticas elencadas para expressar polidez, focamos nas formas pronominais nós/a gente e na forma verbal de FP.

As formas pronominais nós/a gente têm sido utilizadas pelos falantes como estratégia de polidez, ao passo que o uso dessas formas está estritamente atrelado a fatores linguísticos, sociais e pragmáticos, determinando, assim, seu caráter específico ou genérico.

Lopes (1998) critica, em seu estudo, a gramática normativa por tratar a forma nós como mero plural de $e u$, pois, para a autora, não há a possibilidade de nós ser plural de eu já que não se trata de elementos de mesma natureza, não teremos a junção de $e u+e u$, e sim de elementos de naturezas distintas, como eu + tu/você, eu + elelela, eu + vós/vocês, eu + eles/elas, e eu 
+ todos. Esses cinco graus de amplitude do eu traçados por Lopes (1998) trazem a ideia de que as formas de referência à primeira pessoa do plural nem sempre terão o mesmo referente, podendo variar de acordo com o grau de determinação do sujeito, ou seja, vai de um continuum de referentes mais determinados para referentes menos determinados, tendo, esse continuum, pontos de favorecimento de uma ou outra forma.

Estudos que focam a variação nós/a gente e indeterminação do sujeito apontam para a predominância do uso da forma a gente quando o sujeito é mais genérico, o que sugere que a forma pode ser considerada como um recurso de polidez linguística, diferentemente da forma nós. O sentido genérico da forma a gente permite ao falante se descomprometer com o discurso que está sendo proferido. Assim, as formas pronominais de referência à primeira pessoa do plural podem se constituir em estratégias de polidez positiva, negativa ou encoberta.

As estratégias de polidez positiva são direcionadas com intuito de reparar a face positiva do destinatário ou expressar interesse pelo outro. Segundo Brown e Levinson (2011[1987]), as realizações linguísticas de polidez positiva, em muitos casos, podem representar desejos e conhecimentos compartilhados. O excerto (1) ilustra esse tipo de polidez:

F2: No trabalho de Cristiane... que a gente fez sobre aquele negócio do trecho do rio... que a gente foi é que era pra analisar o trecho do rio... (A.G. cdt $_{\text {D.S. }}$ sdt $_{\text {P F }}$ 05).

$\mathrm{O}$ pronome a gente funciona como uma estratégia de marcador de identidade grupal, uma vez que o falante compartilha da mesma atividade do ouvinte, ou seja, ambos participam do grupo de pessoas da disciplina ministrada pela professora Cristiane. Além dessa estratégia de polidez positiva, há interesses compartilhados entre o falante e o ouvinte, o que leva o falante pressupor e declarar pontos em comum.

Já as estratégias de polidez negativa são utilizadas em ações corretoras da face negativa do interlocutor, e geralmente usadas como forma de distanciamento social. O excerto (2) apresenta um FTA com ação reparadora à face negativa do interlocutor.

(2)

F1: ...questão de confiança de... convívio né... até mesmo... nos dias... que nós mulheres estamos no perí- no período pré menstrual é... é a questão assim de até mesmo conviver com uma pessoa em casa a questão que às vezes a gente tá sem paciência... irritado... como é essa questão assim... sua experiência quando você está nesse período a questão de você conviver com uma pessoa assim (e 


$$
\text { tá)... nesse momento assim... (A.G. }{ }_{\mathrm{cdt}} \text { D.C. }{ }_{\mathrm{sdt}} \mathrm{P} \mathrm{F}_{\mathrm{F}} \text { 06). }
$$

A falante introdutora do tópico tem toda a preocupação de contextualizar e utilizar recursos para pedir que sua interlocutora fale de um assunto íntimo, seu comportamento em período de TPM. Para isso, a estratégia de polidez negativa de minimizar a imposição é utilizada, com a primeira pessoa do plural, sugerindo que é um fato comum a ambas e deixando-a mais à vontade para responder o que lhe foi solicitado.

E as estratégias de polidez encoberta são aquelas que permitem que o falante produza um FTA sem se responsabilizar por ele, deixando a interpretação do seu registro de fala a critério do ouvinte. Nesses casos, o falante diz menos do que o necessário ou até mesmo algo diferente do que ele quer dizer. O excerto (3) ilustra estratégia encoberta de polidez.

\section{(3)}

F1: ...principalmente quando vê aquelas cenas de um... de um aluno é de uma criança querendo ba- bater outra alguma ou... tirar brincadeira sem graça... né se você caso presenciasse uma cena dessa qual é qual seria sua reação?

F2: a minha reação? eu ia tentar ajudar né? assim a separar eles dois de brigar da briga e... tentar conversar com eles dois...

F1: você acha que a só a conversa resolve?

F2: não... ia ter que ter mais outros métodos né? mais aí só no caso na hora a gente ia saber né? (D.S. ${ }_{\text {cdt }} J_{\text {. }}$ sdt $_{\text {d }}$ D $\left.M_{F} 04\right)$.

O falante F2 usa a estratégia fazer perguntas retóricas, ao passo que faz uma pergunta sem a intenção de obter respostas, desobedecendo a máxima de qualidade; e ainda utiliza-se da estratégia ser generalizador, deixando em aberto a interpretação do seu ato de fala, uma vez que ele não quis se responsabilizar pelo ato de não saber o que faria para resolver o problema. Então, ao invés de utilizar a primeira pessoa do singular, como vinha utilizando, adotou a primeira pessoa do plural, fato esse que pode ser explicado por não ser apenas ele que não saberia o que fazer. Então não se sabe se assim como ele, F2, outros professores também não saberiam o que fazer, ou se seria ele juntamente com a direção que fariam algo, ou ainda outras possibilidades de interpretação.

Já na gramática normativa, o futuro do pretérito é associado à expressão do valor de polidez (cf. ARAUJO; FREITAG, a sair), em contextos de solicitação, de manifestação de incerteza, ordem ou desejo. O excerto (4) ilustra o uso do futuro do pretérito como estratégia de polidez positiva. Esse excerto aborda o tópico comer determinados alimentos quando algum membro da casa não pode fazê-lo em virtude de problemas de saúde. 
Observe-se que F2 tenta dar razões ou explicações para justificar (estratégia de polidez positiva 13) o fato de que, caso passasse por essa situação, ele comeria alimentos que o outro membro familiar não pode comer apenas quando não estivesse na frente dele. Ao agir dessa forma, F2 tenta preservar a sua face positiva.

F1: mas você comer você comeria escondido era?

F2: não não na frente entendeu? porque é mais difícil né? se eu se você se eu comer na sua frente... e se eu comer na frente deles se eles não podem... eu comer na frente deles é mais difícil de eles resistirem entendeu? eu como evitaria de comer na frente deles...

F1: você iria comer escondido...

F2: não... não comer escondido... não não comeria só apenas na frente... ((RISOS)) (D.S. ${ }_{\mathrm{cdt}} \mathrm{J}_{\text {.S. }}$ sdt $_{\mathrm{f}} \mathrm{D} \mathrm{M}_{\mathrm{F}}$ 04)

No excerto (5) temos um exemplo de uso do futuro do pretérito como estratégia de polidez negativa. Neste exemplo, F1 questiona se F2 voltaria para salvar as pessoas de um algum incêndio. Trata-se de um tópico que coloca em risco a face negativa de F2. Este é o uso do futuro do pretérito como estratégia de polidez negativa de atenuação (estratégia 2) para preservar a sua face.

(5)

F1: então... mas (hes) você disse que "ah se tivesse algum conhecido" $<<$ né $>>$ ?... se geralmente mas geralmente teria porque em boate você nunca vai sozinho $<<$ cề> nunca vai sozinho $<<$ pá $>>$ festa nenhuma... então a tendência é que lá tivesse realmente conhecidos então... você acha que você mudaria então a sua?

F2: ah se tivesse algum conhecido... então se tivesse conhecido acho que... acho que morreria todo mundo junto ((RISOS)) porque eu voltaria <<pra >> tentar salvá-los (E.C. ${ }_{\text {cdt }}$ G.G. ${ }_{\text {sdt }}$ P F $_{\mathrm{M}}$ 34)

Em (6) o futuro do pretérito foi utilizado como uma estratégia de polidez encoberta. Neste excerto, os informantes discorrem sobre a "cura gay”, observe-se que F1 opta por fazer o FTA abertamente sem ação reparadora. Já F2, responde ao questionamento de F1 de maneira vaga (estratégia de polidez encoberta 12) afirmando que não sabe de uma possível solução para a problemática que gira em torno desse assunto.

(6)

F1: não o que eu quero dizer é que você tem dentro dessa colocação de que... de que... não não consegue entender... é... porquê... 
muitos casais se casam homem com homem e mulher com mulher... você tá colocando que você que é... que não consegue entender então como é que quando não consigo entender o problema... e descarto uma possível solução?

F2: porque eu não sei qual será qual seria possível solução entendeu? eu não sei

F1: sim mas até agora que a única que foi levantada foi essa da cura gay

F2: mas eu não sei eu eu nem sabia dessa parte da cura gay entendeu? eu não sabia que tinha levantado assim... essa parte de cura gay (D.S.cdt J.S.sdt D MF 04)

Ainda segundo Brown e Levinson (2011[1987]), há três fatores contextuais que são importantes para entender como as pessoas escolhem as estratégias de polidez que vão utilizar. São eles: o poder que existe entre o falante e o destinatário, o falante tende a ser mais polido quando precisa pedir algo; a distância social entre o falante e o destinatário, as pessoas tendem a ser mais educadas e menos diretas com pessoas estranhas, e menos gentis e mais diretas com pessoas com quem possuem proximidade; e o custo da imposição, que é representado pelo peso social que tem o pedido que o falante faz.

Mas essas escolhas não são aleatórias. Conforme Brown e Levinson (2011 [1987]), o falante faz uma avaliação da quantidade de trabalho de face necessário nos atos, levando em consideração as três estratégias de polidez, chegando à fórmula da figura 3.

\section{Figura 3: Fórmula para avaliar a quantidade de trabalho de face requerida de um FTA.}

$$
W x=D(S, H)+P(H, S)+R x \leq \begin{gathered}
W=\text { quantidade de trabalho de face } \\
x=\text { FTA } \\
D=\text { distância social } \\
S=\text { falante } \\
H=\text { ouvinte } \\
P=\text { poder relativo } \\
R=\text { grau de imposição }
\end{gathered}
$$

Fonte: Brown e Levinson (2011 [1987], p. 76, traduç̃óo nossa).

A distância social (D) é um fator significativo no contexto de polidez, uma vez que a relação existente entre os interlocutores influenciará na escolha linguística e na qualidade da interação. A partir do reflexo da orien- 
tação educacional, podemos ter uma possibilidade de entendimento para essa atitude, pois crescemos ouvindo que não se deve falar com estranhos. Esse comportamento social contribui para a tendência de o falante ser mais polido com quem tem menos familiaridade.

O poder relativo $(P)$ está associado aos diferentes papéis sociais que os falantes ocupam no momento da interação linguística. Dessa forma, podemos inferir que este poder é dedicado a quem tem o domínio do turno naquele momento e que, consequentemente, ao solicitar que seu interlocutor fale sobre algo, há uma tendência de o locutor querer passar o melhor de si por estar em uma posição de destaque.

O grau de imposição $(R)$ se relaciona ao custo que o ouvinte terá em realizar o ato solicitado. O valor desse custo está relacionado à cultura em que os falantes estiverem inseridos e terá maior peso quando atingir a face negativa do ouvinte.

O controle do sexo/gênero por si só não auxilia no desvelamento da fórmula da polidez, mas, ao desdobrar o controle para a simetria/assimetria da interação quanto ao sexo/gênero, podemos avaliar a influência deste fator.

\subsection{PROCEDIMENTOS METODOLÓGICOS}

Utilizamos como corpus para análise a amostra Rede Social de Informantes Universitários de Itabaiana/SE, constituída a partir da aplicação do modelo de coleta de dados baseado em grupo focal, que foi elaborado especificamente para captar os efeitos de polidez nos usos linguísticos. A coleta de dados foi realizada por meio da gravação de interações conduzidas, com informantes selecionados a partir de uma rede social dentro de uma comunidade de prática universitária.

O procedimento consistiu na seleção de 8 informantes para a formação de dois grupos, de modo que aqueles que pertenciam a um grupo tinham relações de proximidade entre si, mas não com os informantes pertencentes ao outro. Cada informante interagiu com 4 pessoas diferentes (um homem e uma mulher, próximos dele; um homem e uma mulher, distantes dele - nos permitindo assim, controlar a influência da distância social e do sexo/gênero no fenômeno em estudo) duas vezes, o que resultou em 32 interações. No primeiro momento, foram coletadas interações produzidas por membros do próprio grupo (relações in-group). No segundo momento, membros de ambos os grupos foram orientados a interagir entre si (relações out-group) (cf. ARAUJO, SANTOS, FREITAG, 2014).

A amostra analisada conta com 32 interações de 40-60 minutos, de 
onde foram extraídas as ocorrências de futuro do pretérito e de nós/a gente para a análise quantitativa. Os dados obtidos dos fenômenos em estudo foram tabulados e submetidos separadamente ao tratamento estatístico de orientação variacionista do pacote GoldVarb X (SANKOFF; TAGLIAMONTE; SMITH, 2005).

\subsection{A EXPRESSÃO DA POLIDEZ}

O controle da variável sexo/gênero foi realizado em nosso estudo de três formas: sexo/gênero (masculino e feminino), tipo de relação (simétrica - interação entre informantes do mesmo sexo -, e assimétrica - interação entre informantes de sexo diferente) e sexo/gênero dos interactantes (homem-homem, homem-mulher, mulher-mulher e mulher-homem). Com esse desdobramento do controle da variável, podemos contribuir para a análise do estereótipo de que mulheres seriam mais polidas do que homens na interação (logo, usariam mais marcas linguísticas de polidez, como o futuro do pretérito, e a forma a gente na primeira pessoa do plural), ao mesmo tempo que poderíamos verificar os efeitos de gênero na interação, como apontado por Holmes (1998) e Freitag (2012), de que interações simétricas entre homens ou entre mulheres seriam mais "confortáveis", com menos atos ameaçadores à face (e, portanto, menos marcar linguísticas de polidez), e que interações assimétricas, por serem potencialmente menos "confortáveis", teriam mais atos ameaçadores à face (e, portanto, mais marcas linguísticas de polidez). O controle do tópico permite verificar os efeitos de poder relativo, nos termos de Brown e Levinson (2011[1987]) e o uso de marcas linguísticas de polidez.

Foram identificadas 1031 ocorrências de formas referentes à primeira pessoa do plural na posição sintática de sujeito, divididas em dois tipos: nós e a gente, tanto na forma expressa quanto na forma não expressa. Para a forma a gente, identificamos 861 ocorrências (83,5\%), com peso relativo de 0,60 , enquanto para a forma nós, 170 ocorrências $(16,5 \%)$, resultados esses que se aproximam dos encontrados no estudo de Seara (2000), na fala de Florianópolis, e de Borges (2004), na comunidade de Pelotas, os quais tiveram $72 \%$ e $74 \%$ respectivamente de utilização da forma a gente. Se comparados aos de Franceschini (2011), na comunidade de Concórdia, e de Borges (2004) na comunidade de Jaguarão, verificamos uma diferença acentuada, já que estes tendem a um grau médio de utilização das duas formas, com $50 \%$ e $53 \%$ de utilização da forma inovadora, respectivamente, contrastando ainda mais ao resultado de Lopes (1998), que teve $42 \%$ de utilização de a gente.

O gráfico 1 apresenta a distribuição das realizações das formas nós/a 
gente por indivíduo.

Gráfico 1: Distribuição de nós e a gente por falante da amostra.

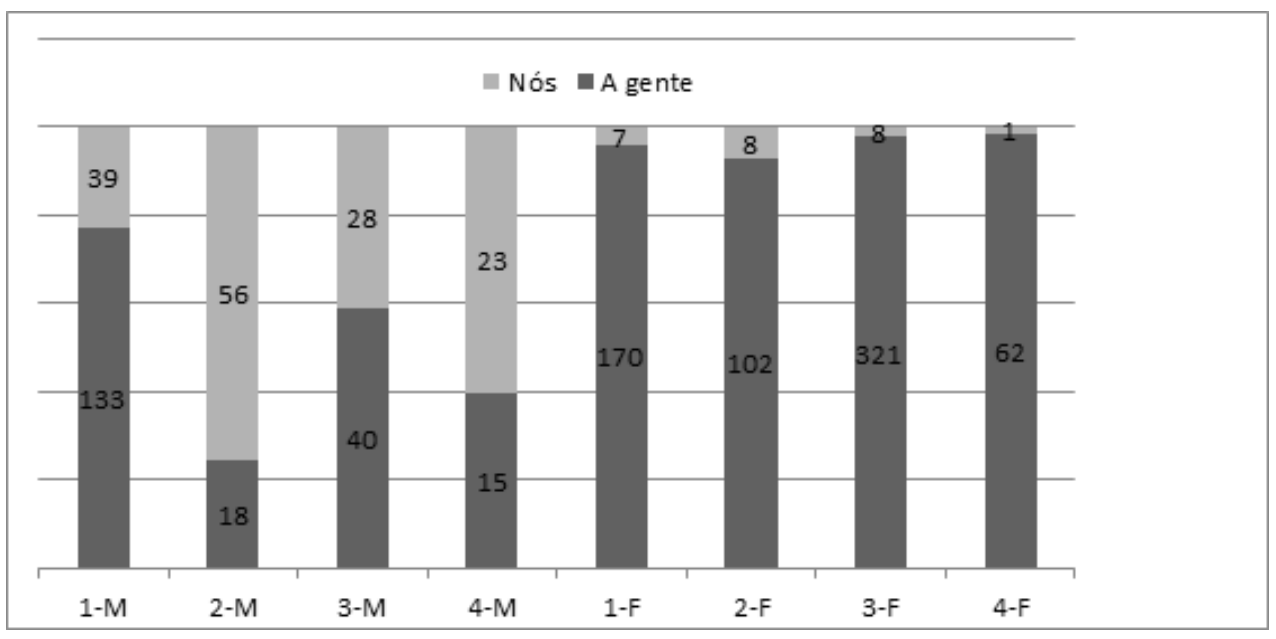

Todos os informantes da amostra usaram as duas variantes, alguns utilizando a forma a gente em menor, e outros em maior proporção, chegando a variar entre $24,3 \%$ (informante $2-\mathrm{M}$ ) e 98,4\% (informante 4-F). A maior regularidade de uso que podemos observar é em relação aos informantes do sexo feminino, pois mantiveram um percentual de aplicação acima de $90 \%$.

Tabela 1: Uso de a gente e o fator sexo/gênero

\begin{tabular}{c|c|c|c}
\hline & Aplic./total & Percentual & Peso Relativo \\
\hline Masculino & $206 / 352$ & $58,5 \%$ & 0,17 \\
Feminino & $655 / 679$ & $96,5 \%$ & 0,69 \\
\hline
\end{tabular}

Informantes do sexo feminino tendem a usar mais a forma a gente, com peso relativo de 0,69 , contrastando com o resultado do sexo masculino, que tende barrar a forma, com peso relativo 0,17 .

Os resultados obtidos com o controle da variável sexo/gênero referentes ao fenômeno da variação na expressão da primeira pessoa do plural corroboram os de Borges (2004), Tamanini (2002), Franceshini (2011), entre outros, de que a variante a gente está sendo utilizada predominantemente pelas mulheres.

Quanto ao futuro do pretérito, foram computadas 671 ocorrências da forma com valor de polidez no corpus sob análise. A diferença de uso entre 
homens e mulheres foi sutil - 50,8\% e 49,2\% respectivamente.

\section{Gráfico 2: Distribuição do uso do futuro do pretérito com valor de polidez} quanto ao sexo/gênero do informante.

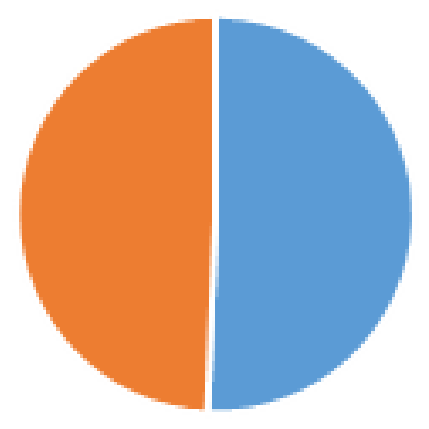

\section{$\square$ homens $\square$ mulheres}

Ainda na perspectiva de analisar os efeitos do sexo/gênero nos usos de nós/a gente e da forma de futuro do pretérito como estratégias polidez, observamos, a partir do que postula Holmes (1998), se as relações entre pares (H-H, M-M) são mais espontâneas e produtivas, e se consequentemente as interações entre pessoas de sexo/gênero opostos (H-M, M-H) são mais breves e formais, pois relações entre pares deixariam os interlocutores mais à vontade, enquanto as relações de sexo/gênero oposto tenderiam a ser mais controladas.

Tabela 2: A influência da interação entre falantes quanto ao sexo/gênero em função de a gente.

\begin{tabular}{c|c|c|c}
\hline & Aplic./total & Percentual & Peso Relativo \\
\hline H-H & $103 / 190$ & $54,2 \%$ & 0,35 \\
H-M & $180 / 213$ & $84,5 \%$ & 0,39 \\
M-H & $242 / 285$ & $84,9 \%$ & 0,47 \\
M-M & $336 / 343$ & $98 \%$ & 0,67 \\
\hline
\end{tabular}

Os resultados da tabela 2 sugerem que a relação entre o sexo dos interlocutores interfere nos resultados. As relações entre $\mathrm{M}-\mathrm{M}$ favorecem o uso da variante a gente, com peso relativo de 0,67. Já as relações $\mathrm{H}-\mathrm{H}$ se encontram no extremo do desfavorecimento, com peso relativo de 0,35 . A simetria das relações mostrou-se um fator significativo, com a polarização de usos de nós em interações $\mathrm{H}-\mathrm{H}$ e a polarização de usos de a gente nas interação M-M, o que só foi possível por contas da metodologia de coleta 
de dados diferenciada.

Quanto à distribuição dos usos do futuro do pretérito em contextos de polidez, os resultados não evidenciam diferenças de usos nas interações entre homens e mulheres, independentemente de quem controla o tópico.

Tabela 3: Influência da interação entre falantes quanto ao sexo/gênero sobre 0 uso da forma de futuro do pretérito em contextos de expressão de polidez

\begin{tabular}{c|c}
\hline & Percentual \\
\hline $\mathbf{H}-\mathbf{H}$ & $25,6 \%$ \\
$\mathbf{H}-\mathbf{M}$ & $24,0 \%$ \\
$\mathbf{M}-\mathbf{M}$ & $20,0 \%$ \\
$\mathbf{M}-\mathbf{H}$ & $30,4 \%$ \\
\hline
\end{tabular}

Os dados de futuro do pretérito com valor de polidez também foram analisados através do controle do tipo de relação, simetria e assimetria, sem considerar quem está com o domínio do tópico.

O controle do sexo/gênero através do tipo de relação se mostrou pouco significativo em nossa análise, uma vez que houve uma sutil diferença nos usos do futuro do pretérito entre homens $(45,6 \%)$ e mulheres $(54,4 \%)$.

\section{Gráfico 3: Distribuição do uso do futuro do pretérito com valor de polidez quanto ao sexo/gênero do informante.}

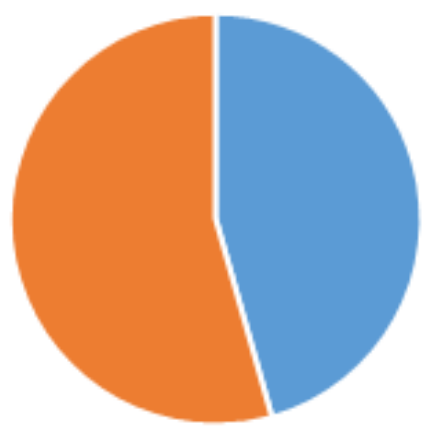

- Simétrica - Assimétrica

Os resultados mostram que os efeitos da variável sexo/gênero em relação à polidez são mais significativos no fenômeno linguístico da variação na expressão da primeira pessoa do plural, ainda pouco explorado sob 
essa perspectiva, do que no futuro do pretérito, canonicamente relacionado à expressão da polidez nas gramáticas normativas.

\section{CONSIDERAC̣õES FINAIS}

A polidez e sua expressão linguística ainda é um domínio pouco explorado na abordagem sociolinguística, especialmente porque requer estratégias diferenciadas para a coleta de dados. No entanto, a experiência apresentada mostrou-se promissora, na medida que permitiu identificar valores de polidez associados a uma variante linguística em interação com o sexo/gênero do informante.

Acreditamos que, a partir deste estudo, outros na mesma perspectiva de análise também possam ser realizados, no intuito de ampliar as discussões acerca dos fenômenos pragmáticos neste campo de estudo. 


\section{REFERÊNCIAS}

ARAUJO, A. S.; SANTOS, K. C.; FREITAG, R. M. Redes sociais, variação linguística e polidez: procedimentos de coleta de dados. In: Metodologia de coleta e manipulação de dados em sociolinguística. São Paulo: Blucher, 2014.

BORGES, P. R. S. A gramaticalização de a gente no português brasileiro: análise histórico-social-linguística da fala das comunidades gaúchas de Jaguarão e Pelotas. Tese (doutorado em Letras). Programa de Pós-Graduação em Letras da Universidade Federal do Paraná. Porto Alegre, 2004.

BROWN, P.; LEVINSON, S. Politeness: some universals in language usage. Cambridge: Cambridge University Press, 2011[1987].

FRANCESCHINI, L. T. Variação Pronominal nós/a gente e tu/você em Concórdia/SC. Tese (Doutorado em Letras) - Programa de Pós-Graduação em Letras. Universidade Federal do Paraná, Curitiba, 2011.

FREITAG, R. M. O controle dos efeitos estilísticos dos papéis sociopessoais e do sexo/gênero na entrevista sociolinguística. In: Anais do II Congresso internacional de dialetologia e sociolinguística, p. 289-296, 2012.

GOFFMAN, E. Interaction Ritual: essays on face-to-face behavior. New York: Doubleday Anchor, 1967.

HOLMES, Janet. Complimenting: A positive politeness strategy. In: COATES, Jennifer (ed.). Language and gender: a reader. Oxford: Blackwell, 1998, p. 100120.

LAKOFF, R. Linguagem e lugar da mulher (1972). In. OSTERMANN, A. C.; FONTANA, B. (orgs.) Linguagem, Gênero, sexualidade. São Paulo: Parábola Editorial, 2010. p 13 - 30.

LOPES, C. R. S. A gramaticalização de a gente em português em tempo real de longa e de curta duração: retenção e mudança na especificação dos traços intrínsecos. Fórum Linguístico, Florianópolis, v. 4, n. 1 (47-80), julho de 2004.

LOPES, C. R. S. Nós e a gente no português falado culto do Brasil. Delta. Vol. 14 n.2 São Paulo, 1998.

SANKOFF, D.; TAGLIAMONTE, S.; SMITH, E. Goldvarb x: variable rule application for Macintosh and Windows. Toronto: University of Toronto, 2005.

SEARA, I. C. A variação do sujeito nós e a gente na fala florianopolitana. Estudos da língua falada, v. 14, n. 28-29. 2000.

TAMANINE, A. M. B. A alternância nós/a gente no interior de Santa Catarina. Dissertação (Mestrado em Letras). Faculdade de Ciências e Letras, Universidade Federal do Paraná, 2002. 